\title{
Linking water quality to larval survival: predation mortality of fish larvae in an oxygen-stratified water column
}

\author{
Denise L. Breitburg ${ }^{1, *}$, Kenneth A. Rose ${ }^{2, * *}$, James H. Cowan $\mathrm{Jr}^{3}$ \\ ${ }^{1}$ The Academy of Natural Sciences, Estuarine Research Center, 10545 Mackall Road, St. Leonard, Maryland 20678, USA \\ ${ }^{2}$ Environmental Sciences Division, PO Box 2008, Oak Ridge National Laboratory, Oak Ridge, Tennessee 37831-6036, USA \\ ${ }^{3}$ University of South Alabama, Dauphin Island Sea Lab, PO Box 369-370, Dauphin Island, Alabama 36528, USA
}

\begin{abstract}
Low dissolved oxygen concentrations can affect growth rates, distributions and predatorprey interactions of aquatic organisms. Each of these potential effects is generally examined separately in laboratory and field studies. As a result, it is often difficult to determine the net influence of low oxygen on survival and which individual effect of low oxygen contributes most to mortality. We used a spatially explicit individual-based predation model to predict how effects of low dissolved oxygen on vertical distributions, predation rates, and larval growth combine to influence survival of estuarine fish larvae in a water column where the subpycnocline (bottom) and pycnocline layers are subject to oxygen depletion. We analyzed simulations involving 3 predators (scyphomedusae based on Chrysaora quinquecirrha, and fish that were relatively sensitive to, or tolerant of, low dissolved oxygen), water columns that differed in the relative thickness of the subpycnocline layer, and bottom dissolved oxygen concentrations ranging from $<1 \mathrm{mg}^{-1}$ to no-effect concentrations. The effect of dissolved oxygen on larval and predator vertical distributions, predator capture success and larval growth rates in simulations were based on previous experiments and field sampling in the Patuxent River, a tributary of the Chesapeake Bay, USA. Simulations indicated that bottom dissolved oxygen can strongly affect predation mortality of fish larvae. Thus, there is the potential for eutrophication to have a large effect on larval fish survival, and possibly recruitment, even in the absence of direct effects of low oxygen-induced mortality of larvae or the effects of nutrient enrichment on the abundance of larval prey or predators. Depending on predator characteristics and water column depth, lowest larval survival occurred when oxygen concentrations were either $<1 \mathrm{mg} \mathrm{l}^{-1}$ or sufficiently high that oxygen concentration had no effect on distributions or capture rates; highest survival generally occurred with hypoxic bottom layers (1 to $2 \mathrm{mg} \mathrm{l}^{-1}$ dissolved oxygen). Bottom dissolved oxygen concentration also strongly affected the relative importance of fish and sea nettle predation in simulations that included both types of predators. Differences among predator types had important consequences for the magnitude and location of predation. Bottom-layer oxygen depletion shifted the focus of trophic interactions into the pycnocline and surface layers. Additional simulations indicated that distributional and capture success effects on larval survival were more important than growth rate effects, and that the direction of effects depended on the predator type and dissolved oxygen concentrations. Limitations of the model as well as implications of results for efforts to reduce nutrient loadings into estuaries are discussed.
\end{abstract}

KEY WORDS: Behavioral responses Chesapeake Bay. Fish predator - Food web - Gelatinous zooplankton - Gobiosoma bosc Hypoxia - Individual-based model

\section{INTRODUCTION}

'E-mail: breit@acnatsci.org

- Present address: Coastal Fisheries Institute and Department of Oceanography and Coastal Sciences, Louisiana State University, Baton Rouge, Louisiana 70808, USA
Low dissolved oxygen concentrations commonly occur in stratified waters. Density differences within the water column isolate bottom waters from the surface mixed layer, enabling microbial respiration of 
excess primary production to reduce dissolved oxygen at depth (Wetzel 1983, Kemp \& Boynton 1992). This phenomenon occurs in a wide range of aquatic habitats including estuaries, nearshore coastal habitats, freshwater lakes and the deep sea (e.g. Sewell \& Fage 1948, May 1973, Taft et al. 1980, Wetzel 1983, Rosenberg 1990, Rabelais et al. 1991). In many cases, excess production and consequent oxygen depletion are associated with high loadings of nutrients from anthropogenic sources (Nixon 1992, 1995).

Dissolved oxygen may impart biologically significant spatial structure to the water column because the surface mixed layer can remain at oxygen concentrations near saturation even when bottom layers are anoxic or have extremely low dissolved oxygen concentrations. At least as early as Huffaker (1958), biologists have recognized that the spatial structure of the environment can influence the persistence of prey populations. More recently, there has been a growing appreciation of the importance of spatial structure to a wide range of ecological interactions and to the maintenance of species diversity (e.g. Molofsky 1994, Tilman 1994).

The vertical oxygen structure of the water column may be especially important in predicting how subpycnocline oxygen depletion will affect trophic interactions. Low dissolved oxygen can directly affect nearly every aspect of predator-prey interactions because both behaviors and physiological processes can be influenced. Encounter rates between predators and their prey can be altered under low dissolved oxygen conditions through shifts in vertical or horizontal distributions (Magnuson et al. 1985, Rudstam \& Magnuson 1985, Kolar \& Rahel 1993, Roman et al. 1993, Breitburg 1994, Howell \& Simpson 1994, Keister 1996), changes in foraging location (Rahel \& Nutzman 1994), and reductions in swimming speeds (Breitburg unpubl. data). Prey capture rates can be further affected by low dissolved oxygen because of decreased feeding activity of predators (Bejda et al. 1987, Breitburg et al. 1994, Petersen \& Pihl 1995), and changes in behaviors of prey that influence their susceptibility to predation (Poulin et al. 1987, Rahel \& Kolar 1990, Pihl et al. 1992, Kolar \& Rahel 1993, Breitburg et al. 1997).

In this paper, we use a spatially explicit individualbased predation model to predict how low dissolved oxygen in a vertically stratified water column will affect survival of estuarine fish larvae being preyed upon by scyphomedusae and fish. The water column is configured to resemble estuarine systems like Chesapeake Bay and its tributaries, where salinity and temperature differences lead to stratification into surface, pycnocline, and bottom layers. Predicting dissolved oxygen effects on larval fish survival is especially important for the management of estuaries because the most important negative effect of excess nutrient loads on fish populations may be summer oxygen depletion in bottom waters. The use of a spatially explicit individual-based model allows for the integration of largescale distributional effects due to dissolved oxygen with small-scale behavioral and physiological changes in an oxygen-stratified water column

\section{METHODS}

General approach. We used a spatially explicit individual-based predation model to predict how effects of dissolved oxygen on vertical distributions, predation rates, and larval growth combine to influence survival of estuarine fish larvae in a water column where the subpycnocline (bottom) and pycnocline layers are subject to oxygen depletion. The basic approach was to define a 3-layer water column with assigned dissolved oxygen concentrations in each layer, and then track the daily position, growth and survival of each individual fish larva for $30 \mathrm{~d}$ as it behaved and interacted with predators according to specified rules. The model used here was based on the individual-based predation models of Cowan et al. $(1996,1997)$, modified to include dissolved oxygen effects and a 3-layer water column. Data on predator behavior and dissolved oxygen effects were collected in the mesohaline Chesapeake Bay, and one of its subestuaries, the Patuxent River, Maryland. Below we describe the role in the Chesapeake Bay food web of the prey and predators simulated in this model, the data we used to modify the original predation model for dissolved oxygen effects, and the original and modified versions of the model.

Chesapeake Bay fish larvae and predators. Our analysis focuses on predation on fish larvae by 2 of their important predators in the Chesapeake Bay system: the scyphomedusa sea nettle Chrysara quinquecirrha (Cowan \& Houde 1993, Purcell et al, 1994) and predatory fishes (e.g. Markle \& Grant 1970). The 2 most abundant fish larvae during summer in the mainstem Chesapeake Bay and its tributaries are the naked goby Gobiosoma bosc and the bay anchory Anchoa mitchilli (e.g. Dovel 1971). Naked goby tend to be numerically dominant in the tributaries, while bay anchovy is the more abundant species in the mainstem Bay. We based our simulated fish larvae (the prey) on naked goby because this species was more abundant than bay anchovy in our field samples from the Patuxent River that were used to determine effects of dissolved oxygen on vertical distributions, and is more tolerant of handling than bay anchovy in experimental manipulations. Our field and laboratory data suggest that larvae of the 2 species respond very similarly to low dissolved oxygen (Breitburg 1994, Keister 1996, 
Breitburg et al. 1997). However, an important difference between the species not considered in our analysis is the difference in their spawning behaviors. The naked goby has benthic guarded eggs that hatch into larvae competent to immediately begin feeding. Naked goby eggs are primarily found in oyster reefs within the oxygenated surface water layer, but can suffer mortality from exposure to hypoxic or anoxic conditions during wind-induced intrusions of bottom water into nearshore habitats (Breitburg 1992). In contrast, bay anchovy spawn pelagic eggs that hatch out as prefeeding yolk-sac larvae. When subpycnocline waters are severely hypoxic or anoxic, substantial numbers of bay anchovy eggs may sink below the pycnocline (Keister 1996) and constitute an important source of mortality that is not included in our model. Furthermore, the ability of 0 to $2 \mathrm{~d}$ posthatch (dph) yolk-sac bay anchovy larvae to avoid low dissolved oxygen is unknown.

Sea nettles and predatory fishes account for substantial mortality of fish larvae in the Chesapeake Bay. For example, in a study conducted in the mainstem Chesapeake Bay, Purcell et al. (1994) estimated that sea nettles consumed $29 \%$ of bay anchovy larvae $\mathrm{d}^{-1}$, which represented $41 \%$ of their total estimated daily mortality. Cowan \& Houde (1993) suggested that the sea nettle may be the most important predator of summer ichthyoplankton in Chesapeake Bay because of the sea nettle's high abundance during times of peak larval densities and its high feeding rate. Although daily mortality of Chesapeake Bay fish larvae due to fish predation has not been estimated, mesocosm experiments (Cowan \& Houde 1993) and field collections (e.g. Markle \& Grant 1970, Boynton et al. 1981) indicate that juvenile and small adult fishes are important consumers of fish larvae. For example, fish larvae (primarily naked goby) can, at times, comprise over $40 \%$ of the diet of juvenile striped bass Morone saxatilis in Chesapeake Bay tributaries (Markle \& Grant 1970, Boynton et al, 1981). Two hypothetical fish predators are used in the simulations: 'sensitive' and 'tolerant' fish that differ in the dissolved oxygen concentrations that affect their predation rates and distributions. Effects of low dissolved oxygen on the sensitive fish predator are based on information available for juvenile striped bass. There is not a particular 'tolerant' fish species upon which simulation of the tolerant fish predator are based. However, we felt it was important to include this model predator in simulations as a contrast to the sensitive fish predator. There are a number of fish species in the Chesapeake Bay and other similar estuarine systems that prey on larvae and that are more tolerant of low dissolved oxygen than striped bass, but for whom little or no data exist on behavioral responses to low dissolved oxygen.
Model description. Basic model: The individualbased model tracked the daily growth and survival of individual members of a larval fish cohort over $30 \mathrm{~d}$ as they were exposed to predation by individual sea nettles, fish predators, or a combination of the 2 predator types. Initial numbers of prey and predators, and the volume of the modeled system, were specified to obtain realistic densities and to yield sufficient numbers of surviving larvae at the end of the simulations to permit meaningful interpretation (See 'Design of simulations' below).

On the first day of a simulation, each larval fish was randomly assigned an initial length $\left(L_{L}, \mathrm{~mm}\right)$ and each individual predator was assigned an initial length $\left(L_{P}\right.$, $\mathrm{mm}$ ), from normal distributions with specified means, standard deviations, and minimum and maximum values. Minimum and maximum values were specified to eliminate unrealistic values from the distributions of length and growth rates and to limit fish predators to sizes used in experiments. We assigned the same baseline (i.e. $\geq 4 \mathrm{mg} \mathrm{I}^{-1}$ dissolved oxygen) larval growth rate $\left(G_{\mathrm{L}}\right)$ to all larvae (i.e. $\mathrm{SD}=0$ ) because we did not intend to focus on how variation in growth rates among individuals affected survival. Larvae maintained their assigned baseline growth rate throughout the simulations, but realized growth of each larva was adjusted daily depending on the dissolved oxygen concentration of the water layer in which it was located.

On each day of the simulation, the length of each larva was incremented by its dissolved-oxygenadjusted growth rate and then evaluated to determine whether it had encountered and been captured by a predator. The predators were assumed not to satiate when feeding on ichthyoplankton (Cowan \& Houde 1992, 1993). Encounter rate was determined using the Gerritsen-Strickler formulation (Gerritsen \& Strickler 1977), modified to account for the non-negligible size of fish larvae prey (Bailey \& Batty 1983). Both encounter and capture were treated as stochastic processes. The mean number of encounters in a day $(\bar{E})$ between each individual prey and predator was computed by:

$$
\bar{E}=\pi\left(R_{\mathrm{L}}+R_{\mathrm{P}}\right)^{2} \times C \times\left(10^{-9} / V\right)
$$

where

$$
\begin{aligned}
& C=\frac{D_{\mathrm{L}}^{2}+3 D_{\mathrm{P}}^{2}}{3 D_{\mathrm{P}}^{2}} \text { if } D_{\mathrm{p}}>D_{\mathrm{L}} \\
& C=\frac{D_{\mathrm{P}}^{2}+3 D_{\mathrm{L}}^{2}}{3 D_{\mathrm{L}}^{2}} \text { if } D_{\mathrm{p}}<D_{\mathrm{L}}
\end{aligned}
$$

$C=$ foraging rate $\left(\mathrm{mm} \mathrm{s}^{-1}\right) ; R_{\mathrm{p}}=$ encounter radius of the predator $(\mathrm{mm}) ; R_{\mathrm{L}}=$ encounter radius of the larva $(\mathrm{mm})_{i} D_{\mathrm{p}}=$ distance swum in a day by the predator $(\mathrm{mm})_{i} D_{\mathrm{L}}=$ distance swum in a day by the larva prey $(\mathrm{mm})$; and $V=$ modeled volume $\left(\mathrm{m}^{3}\right)$. 
$\bar{E}$ is thus the mean number of times in a day that the encounter volume of the larva entered the encounter volume of the predator. Eq. (1) was derived under the following assumptions: (1) predators and prey are randomly distributed in space; (2) swimming by predators and prey is random in direction; (3) encounter volume of the predator is a cylinder with its base having a radius equal to the encounter radius of the predator and its height equal to the distance swum by the predator in a day; (4) encounter volume of a larva is a sphere with radius equal to its encounter radius; and (5) a predatory fish does not search for prey below its body, i.e. its encounter volume is a half-cylinder (Rosenthal \& Hempel 1970, Fuiman \& Gamble 1989). Fish species vary in how well each of these assumptions describe their predation behavior. As indicated previously, we were simulating generalized fish predators, not a particular species. The half-cylinder encounter volume and 3 body lengths $\mathrm{s}^{-1}$ search velocity (see below) used in these simulations were based on clupeioid fish; fish such as juvenile striped bass, which feed both on the benthos and in the water column, likely have a more nearly completely cylindrical search volume, but a lower search velocity (Leucke \& O'Brien 1981, Walton et al. 1994).

The actual numbers of encounters and successful captures were generated from the mean encounter rate $(\bar{E})$ and the capture success of the predator for that larva. Actual number of encounters was generated as a random deviate from a Poisson distribution with mean $=\bar{E}$. The number of encounters that resulted in a successful capture of a larva was then determined from a binomial distribution, with the number of actual encounters used as the number of trials, and the predator capture success as the probability of success of each trial. For each larva, this process was repeated for each of the individual predators. If at least 1 encounter between a larva and predator resulted in a successful capture, the larva was 'eaten' and was removed from the cohort. Numbers, lengths, growth rates, and locations of surviving larvae and those that died were recorded each day for the $30 \mathrm{~d}$ simulation.

Parameter values for basic model: Empirical information on fish larvae, sea nettles, and fish predators used in the basic (i.e. high dissolved oxygen in 1 spatial box) model formulation were derived from an extensive array of field, mesocosm, and laboratory studies conducted in the mainstem Chesapeake Bay and the Patuxent River. Values for initial larval lengths were $2.8 \pm 0.5(\mathrm{SD}) \mathrm{mm}$ (range $=2.3$ to $3.2 \mathrm{~mm}$ ) based on laboratory hatching of Chesapeake Bay naked goby by D.L.B. The baseline (i.e. $\geq 4 \mathrm{mg} \mathrm{l}^{-1}$ dissolved oxygen) larval growth rate was set at $0.23 \mathrm{~mm} \mathrm{~d}^{-1}$ based on laboratory rearing and aging of field collected larvae (Breitburg 1989 unpubl. data). Sea nettle lengths were set to $69.0 \pm 33.0$ (SD) $\mathrm{mm}$ bell diameter (range $=5.0$ to $15.0 \mathrm{~cm}$ ) based on collections in the Patuxent River (Keister 1996) and sizes used in experiments. Lengths of hypothetical sensitive and tolerant fish predators were $50.0 \pm 25.0 \mathrm{~mm}$ standard length (range $=35.0$ to $65.0 \mathrm{~mm}$ ) to limit simulations to the range of fish predator sizes used in experiments on dissolved oxygen effects described below.

Parameters values for capture success and encounter rates for both sea nettles and predatory fishes were derived from results of laboratory and in situ mesocosm experiments performed at high dissolved oxygen concentrations (Cowan \& Houde 1990, 1992, 1993, Cowan et al. 1992), and are the same as those used in Cowan \& Houde $(1992,1993)$ and Cowan et al. (1996, 1997). To estimate larval susceptibility (realized capture probability), predators were allowed to feed in $24 \mathrm{~h}$ mesocosm experiments on goby larvae ranging from 2 to $>10 \mathrm{~mm}$ total length. Because the mean number of larvae consumed by each predator type in each $1 \mathrm{~mm}$ larval length class was known, susceptibility by definition was the ratio of the number of larvae eaten in each size class to the number of probable encounters between predators and larvae in that length class (Cowan et al. 1996). Capture success of medusae and fish predators were specified as cubic functions of predator length. Capture success of medusae decreased slowly from 0.8 at a $2 \mathrm{~mm}$ prey length to 0.45 at $6 \mathrm{~mm}$, and then decreased more rapidly to 0.125 at $10 \mathrm{~mm}$ prey length (capture success $=0.505+0.082 L_{\mathrm{L}}$ $\left.-0.020 L_{\mathrm{L}}{ }^{2}+0.0008 L_{\mathrm{L}}{ }^{3}\right)$. Capture success of fish predators decreased slowly from 0.2 at a prey length of $2 \mathrm{~mm}$ to 0.09 at $10 \mathrm{~mm}$ (capture success $=0.18+0.015 L_{\mathrm{L}}-$ $\left.0.0033 L_{\mathrm{L}}{ }^{2}+0.0001 L_{\mathrm{L}}{ }^{3}\right)$. Agreement between estimates of sea nettle predation rates outside of enclosures (Purcell et al. 1994) and within in situ mesocosm experiments is good; both methods yielded larval mortality estimates of $40 \% \mathrm{~d}^{-1}$ for July at the site sampled. Similar direct comparisons for fishes are not available, but may be less relevant because we are attempting to simulate hypothetical fish that differ in their sensitivity to low dissolved oxygen rather than to simulate a particular species.

The encounter radius $\left(R_{\mathrm{L}}\right)$ of a fish larva was estimated as $2 L_{L} / \pi^{2}$ where $L_{L}$ is length of the larva in $\mathrm{mm}$ (Bailey \& Batty 1983). The distance swum $\left(D_{\mathrm{L}}\right)$ by a larva in a day is $1.5 L_{\mathrm{L}} \times 46800 \mathrm{~s} . D_{\mathrm{L}}(\mathrm{mm})$ is based on an assumed larval swimming speed of 1.5 body lengths $\mathrm{s}^{-1}$ (Blaxter 1986) for $13 \mathrm{~h} \mathrm{~d}^{-1}$. Encounter radius $\left(R_{\mathrm{P}}\right)$ for sea nettles was the radius of the medusa bell. Distance swum $\left(D_{\mathrm{P}}\right)$ by sea nettles was estimated from measurements in the laboratory and from determinations ( $24 \mathrm{~h}$ experiments in $3.2 \mathrm{~m}^{3}$ mesocosm enclosures) of clearance rates of fish eggs, assuming that immobile fish eggs had a capture probability of 1.0. Distance swum 
was computed assuming activity for $24 \mathrm{~h} \mathrm{~d}^{-1}$ as $1.2+$ 0.04 bell diameter $\times 86400 \mathrm{~s}$. The sensitive and tolerant fish predators were assumed to search at 3 body lengths $\mathrm{s}^{-1}$ (Ware 1978) for $13 \mathrm{~h} \mathrm{~d}^{-1}$ and to have encounter radii of $80 \%$ of their lengths $\left(=0.8 L_{P}\right)$ based on clearance rates of planktivorous fish (Cowan \& Houde 1992).

Predation in an oxygen-structured water column: The basic model was modified to include effects of dissolved oxygen by dividing the water column into surface, pycnocline, and bottom layers. Each day of the simulation, each surviving predator and larva was assigned to one of the water column layers. The probability of assignment to any particular layer was based on the species-specific relationship between the proportional density of individuals in each layer of the water column and the bottom dissolved oxygen concentration (Fig. 1). The growth of each individual larva each day was dependent on the oxygen concentration in the water column layer to which it was assigned Predation mortality in each layer of the water column was dependent on the number and sizes of larvae and predators in that layer, and how the dissolved oxygen concentration of that layer affected capture success rates.

Parameter value adjustments for dissolved oxygen effects: Dissolved oxygen was assumed to modify the vertical distributions of larvae and predators, predator capture success, and larval growth rate. The effect of bottom dissolved oxygen on the vertical distributions of fish larvae and sea nettles (Fig. 1a,b) was estimated from field sampling in which we made repeated discrete depth collections above, below and within the pycnocline at 2 sites in the Patuxent River (Keister 1996). Fish larvae were rare or absent in bottom-layer samples, but were at high densities within the pycnocline when bottom dissolved oxygen was $<2.0 \mathrm{mg} \mathrm{l}^{-1}$. Similarly, larvae as young as $1 \mathrm{dph}$ avoided a lowoxygen bottom layer in laboratory aquaria that maintained a stratified water column, indicating the likelihood that low numbers of larvae in severely hypoxic and anoxic bottom waters in the field are mostly due to avoidance of oxygen-depleted subpycnocline layers, not mortality directly related to low-oxygen exposure (Breitburg 1994). Sea nettle densities in Patuxent River collections were low in bottom-layer samples collected at dissolved oxygen concentrations $<3 \mathrm{mg} \mathrm{l}^{-1}$ and were high within the pycnocline at both very low and high bottom oxygen concentrations (Keister 1996). The vertical distribution of sea nettles appeared to more closely reflect that of their copepod prey, rather than sea nettle tolerances to low oxygen (Keister 1996). For the model, the proportion of larvae and sea nettles in equal volumes of bottom, surface and pycnocline layers (proportional densities) were

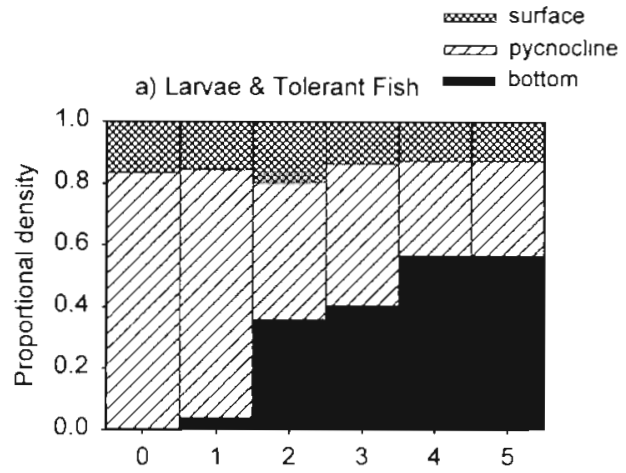

b) Sea Nettles

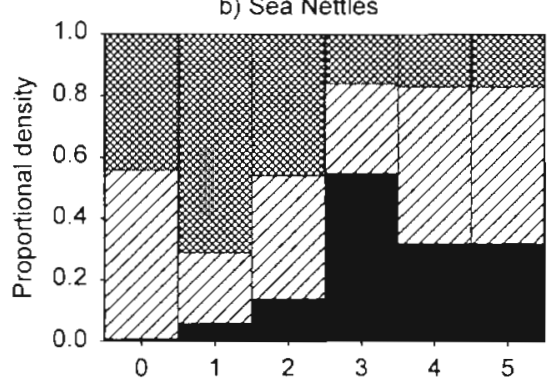

c) Sensitive Fish

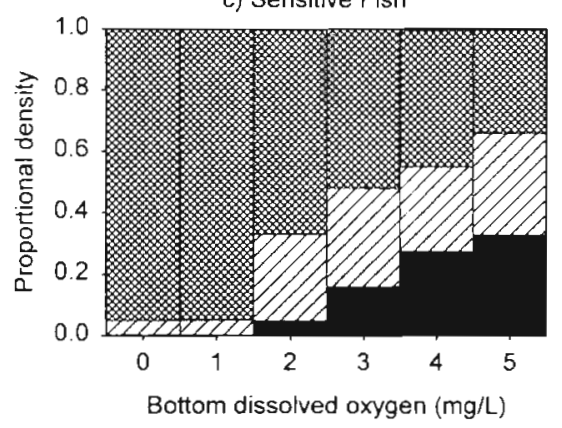

Fig. 1. Proportional densities of fish larvae and predators. (a) Larvae and tolerant fish predators, (b) sea nettles, (c) sensitive fish predators. Proportional densities are calculated as the proportion of individuals that would be in surface, pycnocline and bottom water layers if all layers of the water column were equal in volume. Larval and sea nettle densities are calculated from cruise samples collected during 1992 and 1993 in the Patuxent River (Keister 1996). Larval data are for naked goby larvae. Sensitive fish distributions are based on information for striped bass. These distributions assume that fish will be randomly distributed throughout the water column at oxygen concentrations above those that reduce feeding rates, and that fish will avoid bottom oxygen concentrations that reduce their ability to feed or have been associated with reduced abundances in other studies

averaged over all samples in $1.0 \mathrm{mg} \mathrm{l}^{-1}$ bottom dissolved oxygen intervals (i.e. all samples with bottom dissolved oxygen concentrations of 0.0 to $0.99 \mathrm{mg} \mathrm{l}^{-1}$, 1.0 to $1.99 \mathrm{mg} \mathrm{l}^{-1}$, etc.).

The sensitive fish predator in model simulations moved into pycnocline and surface layers (avoided the bottom layer) at higher bottom-layer dissolved oxygen 
concentrations than did the hypothetical tolerant fish predator. Sensitive fish were randomly distributed throughout the water column at dissolved oxygen concentrations $\geq 5 \mathrm{mg} \mathrm{l}^{-1}$, and shifted into the surface layer as bottom dissolved oxygen concentrations declined below $5 \mathrm{mg} \mathrm{l}^{-1}$ (Fig. 1c). Dissolved oxygen concentrations leading to avoidance of bottom waters by the sensitive fish are based on literature values for juvenile striped bass (Coutant 1985), unpublished data from Maryland Department of Natural Resources (S. Jordan, Maryland Department of Natural Resources, pers. comm.), and laboratory and field observations by D.L.B. In lieu of field data to indicate the proportion of juvenile striped bass that move into the pycnocline versus the surface layer when bottom dissolved oxygen is low, sensitive fish in simulations moved into the surface layer when the bottom layer was less than $5 \mathrm{mg}$ $\mathrm{I}^{-1}$. Avoidance of the pycnocline for bottom dissolved oxygen concentrations $<5 \mathrm{mg} \mathrm{l}^{-1}$ is reasonable because corresponding pycnocline oxygen concentrations should elicit at least partial avoidance by sensitive fish species such as striped bass. In both field measurements (Keister 1996) and simulations, dissolved oxygen in the pycnocline layer was $\leq 4 \mathrm{mg} \mathrm{l}^{-1}$ when the bottom dissolved oxygen was $<5 \mathrm{mg} \mathrm{l}^{-1}$. Vertical distributions used for tolerant fish allow for greater use of low-oxygen water and, in the simulations shown here, are identical to those of the simulated fish larvae (Fig. 1a).

Dissolved oxygen effects on predation rates are incorporated in the model as a multiplier of predator capture success (Fig. 2), which is modified for dissolved oxygen effects based primarily on mesocosm experiments that examined predation on naked goby larvae by sea nettles and juvenile striped bass (Breitburg et al. 1997). Linear interpolation and results of smaller-scale experiments (Breitburg et al. 1994) were used to estimate effects of dissolved oxygen on predation rates for dissolved oxygen concentrations not directly tested in mesocosms. Mesocosm and smallscale experiments indicated that predation on fish larvae by sea nettles increases at low dissolved oxygen concentrations but predation by fishes decreases. In addition, the no-effect dissolved oxygen concentration is lower for sea nettles than for sensitive fish predators such as juvenile striped bass. The tolerant fish was modeled to experience the same reduced magnitude of prey capture rates as the sensitive fish, but the predation reduction was shifted to occur at $1 \mathrm{mg} \mathrm{l}^{-1}$ lower dissolved oxygen.

Varying only the capture success component of predation rates as a function of dissolved oxygen is a simplifying assumption. Low dissolved oxygen modifies several aspects of predator-prey interactions that can affect predation rates (Breitburg 1994, Breitburg et al.

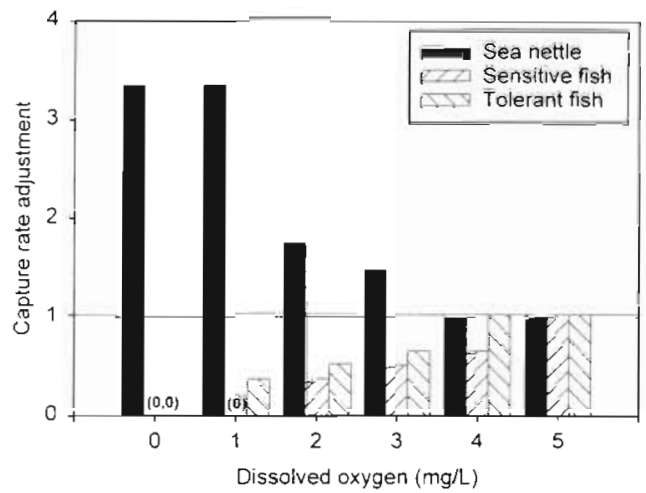

Fig, 2. Dissolved oxygen effects on predator capture rates. Baseline capture rates are at the no-effect oxygen concentration and assumed equal to the capture rates calculated by Cowan et al. (1996). These baseline rates are then multiplied by the appropriate factor derived from mesocosm experiments that tested dissolved oxygen effects on prey capture by sea nettles and juvenile striped bass (sensitive fish). Tolerant fish experience reduced prey capture at dissolved oxygen concentrations $1 \mathrm{mg} \mathrm{l}^{-1}$ lower than those that affect the sensitive fish

1997). For example, burst swim speeds of naked goby larvae decrease at low dissolved oxygen concentrations, presumably increasing their vulnerability to predator attacks. Juvenile striped bass and adult naked gobies (used as 'tolerant' predators in some small-scale experiments with late-stage larvae) became either agitated or lethargic but generally reduced their attack rates at low dissolved oxygen concentrations. In contrast, beil contraction rates, and therefore presumably swimming speeds of sea nettles, are not significantly affected by dissolved oxygen concentrations $\geq 1 \mathrm{mg} \mathrm{l}^{-1}$ (Breitburg 1994, Breitburg et al. 1997). However, our experimental results did not allow us to quantitatively partition dissolved oxygen effects among the various components of predation (e.g. predator swimming speeds, prey escape, predator attack). We therefore considered modification of only final predation rates via capture success to be a reasonable approach because it encompasses in a simple way the combined effects of dissolved oxygen on the individual components of predator-prey interactions.

The reduction of larval growth rates at low dissolved oxygen concentrations is included in the model because predation rates of both sea nettles and fish predators vary with prey size (Cowan \& Houde 1992) In preliminary experiments, growth, feeding rates and 2 wk survival of naked goby larvae were similar in $4 \mathrm{mg} \mathrm{l}^{-1}$ and air-saturated dissolved oxygen treatments (E. Houde \& C. Zastrow unpubl. data). In $1 \mathrm{~h}$ experiments, feeding rates at $2.0 \mathrm{mg} \mathrm{l}^{-1}$ were only $23 \%$ that of air-saturated controls for 2 to $11 \mathrm{~d}$ posthatch larvae feeding on rotifers, and $55 \%$ that of air-saturated controls for 15 to $23 \mathrm{~d}$ posthatch larvae feeding on Artemia 
nauplii. Growth rates of survivors in $14 \mathrm{~d}$ duration experiments were 48 and $80 \%$ of those in air-saturated controls at 1.6 and $2.2 \mathrm{mg} \mathrm{l}^{-1}$, respectively. However, $14 \mathrm{~d}$ survival was only 12 and $16 \%$ that of controls for larvae reared at dissolved oxygen concentrations of 1.6 and $2.2 \mathrm{mg} \mathrm{l}^{-1}$, respectively. We assume here that much of the high mortality measured at the 1.6 and $2.2 \mathrm{mg} \mathrm{l}^{-1}$ oxygen concentrations was of larvae that fed and grew poorly. Growth rate adjustments selected for dissolved oxygen effects on growth rates in this model were, therefore, a compromise that considered effects of dissolved oxygen on short-term feeding, mortality, and growth of survivors described above and were specified as $100 \%$ of baseline $\left(0.23 \mathrm{~mm} \mathrm{~d}^{-1}\right)$ at $4 \mathrm{mg} \mathrm{l}^{-1}$, $60 \%$ of baseline at $3 \mathrm{mg} \mathrm{l}^{-1}, 20 \%$ of baseline at $2 \mathrm{mg}^{1^{-1}}$, and 0 at $\leq 1 \mathrm{mg} \mathrm{l}^{-1}$.

Design of simulations: Two sets of simulations were performed. The first set investigated the effects of predator type, bottom dissolved oxygen concentrations, and water column depth on larval survival. The second set of simulations evaluated the relative importance of dissolved-oxygen-related changes in capture success, distribution, and larval growth rate to predicted larval survival. Predictions from single simulations, all using the same random number sequence, are presented. Predicted larval survival at $30 \mathrm{~d}$ varied by $<5 \%$ among triplicate simulations that differed only by the random number sequence used.

All simulations used 75 sea nettles or 25 fish predators unless otherwise noted. With these predator densities, predation by sea nettles and the sensitive fish predator resulted in roughly similar larval survival rates under high bottom-layer dissolved oxygen concentrations. Simulations with single predator types began with 10000 initial larvae in a $2000 \mathrm{~m}^{3}$ volume water column. These values yielded prey and predator densities typical for the Chesapeake Bay (Dovel 1971 . Brownlee \& Jacobs 1987, Dalton 1987, Horwitz 1987. Olson 1987, Keister 1996) and yielded sufficient numbers of surviving larvae at the end of the simulations to permit meaningful interpretation. Simulations with 2 predator types used twice the number of initial larvae and twice the total volume to minimize prey depletion effects resulting from 2 predators. Doubling the initial number of larvae and volume was chosen, rather than halving the predator densities, because of the potential problem of high variability resulting from assigning a small number of predators to different layers in the water column.

The first set of simulations consisted of 48 model runs involving all combinations of 4 predator treatments, 4 bottom dissolved oxygen concentrations, and 3 differently shaped water columns. The 4 predator treatments were: sea nettles, sensitive fish predator, tolerant fish predator, and sea nettles and sensitive fish predators together. Simulations involving single predator types can be directly compared to evaluate effects of predator type on larval survival. Larval fish in nature are actually exposed to a mix of predator types that vary in time and space. We use a simple predator mix of sea nettles and the sensitive fish predator together as a first step in investigating the effects of predator mixes on larval fish survival where predators differ in their response to dissolved oxygen.

The 4 bottom dissolved oxygen concentrations simulated were 0,1 , and $2 \mathrm{mg} \mathrm{l}^{-1}$ (based on field and experiment data for 0.0 to $0.99,1.0$ to $1.99 \mathrm{mg} \mathrm{l}^{-1}$, and 2.0 to $2.99 \mathrm{mg} \mathrm{l}^{-1}$, respectively) and a no-effect (high) concentration (Table 1). The no-effect concentration was $4 \mathrm{mg} \mathrm{l}^{-1}$ for sea nettles and the tolerant fish predator and $5 \mathrm{mg} \mathrm{l}^{-1}$ for the sensitive fish predator (Figs. $1 \& 2$ ). Based on field data (Keister 1996), the pycnocline was assigned a dissolved oxygen concentration of $3 \mathrm{mg} \mathrm{l}^{-1}$ when the bottom layer concentration was $0 \mathrm{mg}^{-1}$. $4 \mathrm{mg} \mathrm{l}^{-1}$ when the bottom layer was 1 , 2 , or $4 \mathrm{mg} \mathrm{l}^{-1}$, and $5 \mathrm{mg} \mathrm{l}^{-1}$ when the bottom layer concentration was $5 \mathrm{mg} \mathrm{l}^{-1}$. The surface layer was always maintained at the no-effect concentration. The oxygen structure of the water column remained constant throughout each 30 d simulation.

The shape of the water column was varied to test the importance of the proportion of water column susceptible to oxygen depletion. The proportion of the water column in the surface, pycnocline, and bottom layers was varied by simulating water columns of different total depths, while maintaining a constant total volume and a pycnocline depth of $4 \mathrm{~m}$ and thickness of $2 \mathrm{~m}$. The deep water column simulated a $20 \mathrm{~m}$ deep site with $20 \%$ of its volume in the surface layer, $10 \%$ in the pycnocline, and $70 \%$ in the bottom layer $(20: 10: 70 \%)$. The intermediate depth water column simulated a $10 \mathrm{~m}$ deep site with relative layer proportions of 40:20:40\%, and the shallow water column simulated

Table 1. Dissolved oxygen concentrations used in simulations of predation in a 3-layer water column.

\begin{tabular}{|c|c|c|c|}
\hline $\begin{array}{l}\text { Predator } \\
\text { type }\end{array}$ & $\begin{array}{l}\text { Bottom } \\
\text { dissolved } \\
\text { oxygen } \\
\left(\mathrm{mg} \mathrm{l}^{-1}\right)\end{array}$ & $\begin{array}{c}\text { Pycnocline } \\
\text { dissolved } \\
\text { oxygen } \\
\left(\mathrm{mg} \mathrm{l}^{-1}\right)\end{array}$ & $\begin{array}{c}\text { Surface } \\
\text { dissolved } \\
\text { oxygen } \\
\left(\mathrm{mg} \mathrm{l}^{-1}\right)\end{array}$ \\
\hline Sea nettles & 0 & 3 & No effect (4) \\
\hline \multirow{3}{*}{ and tolerant fish } & 1 & 4 & No effect (4) \\
\hline & 2 & 4 & No effect (4) \\
\hline & No effect (4) & 4 & No effect (4) \\
\hline Sensitive fish and & 0 & 3 & No effect (5) \\
\hline sea nettles/sensitive & 1 & 4 & No effect (5) \\
\hline fish combined & 2 & 4 & No effect (5) \\
\hline simulations & No effect (5) & 5 & No effect (5) \\
\hline
\end{tabular}


an $8 \mathrm{~m}$ deep site with layer proportions of 50:25:25\%.

For the first set of simulations, model predictions of larval survival (\%) to Day 30 and the proportion of total predation events (over the $30 \mathrm{~d}$ ) that occurred in each layer were compared among simulations. The location of predation events is reported for 0,2 and 4 to $5 \mathrm{mg} \mathrm{l}^{-1}$ dissolved oxygen; to simplify interpretation, we do not report the location results for $1 \mathrm{mg} \mathrm{l}^{-1}$ dissolved oxygen simulations because they were generally intermediate to the 0 and $2 \mathrm{mg} \mathrm{l}^{-1}$ results. For the simulations involving the predator mix of sea nettles and sensitive fish, we also compare the proportion of predation events by predator type for the shallow and deep water columns.

The second set of simulations was used to quantify the relative importance to larval survival of dissolved oxygen effects on predator capture success, vertical distributions, and larval growth rate. A total of 54 model runs were performed involving all combinations of the 3 predator types (alone) at bottom dissolved oxygen concentrations of 0 and $2 \mathrm{mg} \mathrm{l}^{-1}$ in each of the 3 water column depths. For each combination, larval survival was predicted from simulations in which (1) capture success, (2) larval and predator distributions, and (3) larval growth were all allowed to vary with dissolved oxygen and then with 2 of these factors adjusted for low oxygen effects while the third factor was held at its high (no-effect) dissolved oxygen value. The contribution of each factor to the total dissolved oxygen effect was estimated as the ratio of the survival rate when that particular factor was not adjusted to the survival rate when all 3 factors were allowed to be influenced by dissolved oxygen. A ratio value of 1 means that the dissolved-oxygenrelated changes in that factor had no effect on predicted survival. Ratio values $>1.0$ imply that factor, when allowed to vary with dissolved oxygen concentration, caused a reduction in larval survival (i.e. without its effect larval survival was higher than with its effect). Ratio values $<1.0$ imply that factor caused an increase in larval survival.

\section{RESULTS}

\section{General patterns}

Larval survival in simulations varied with bottom dissolved oxygen concentration, water column depth, which aspects of predator-prey interactions were adjusted for dissolved oxygen effects, and predator type. Because interactions between factors were often
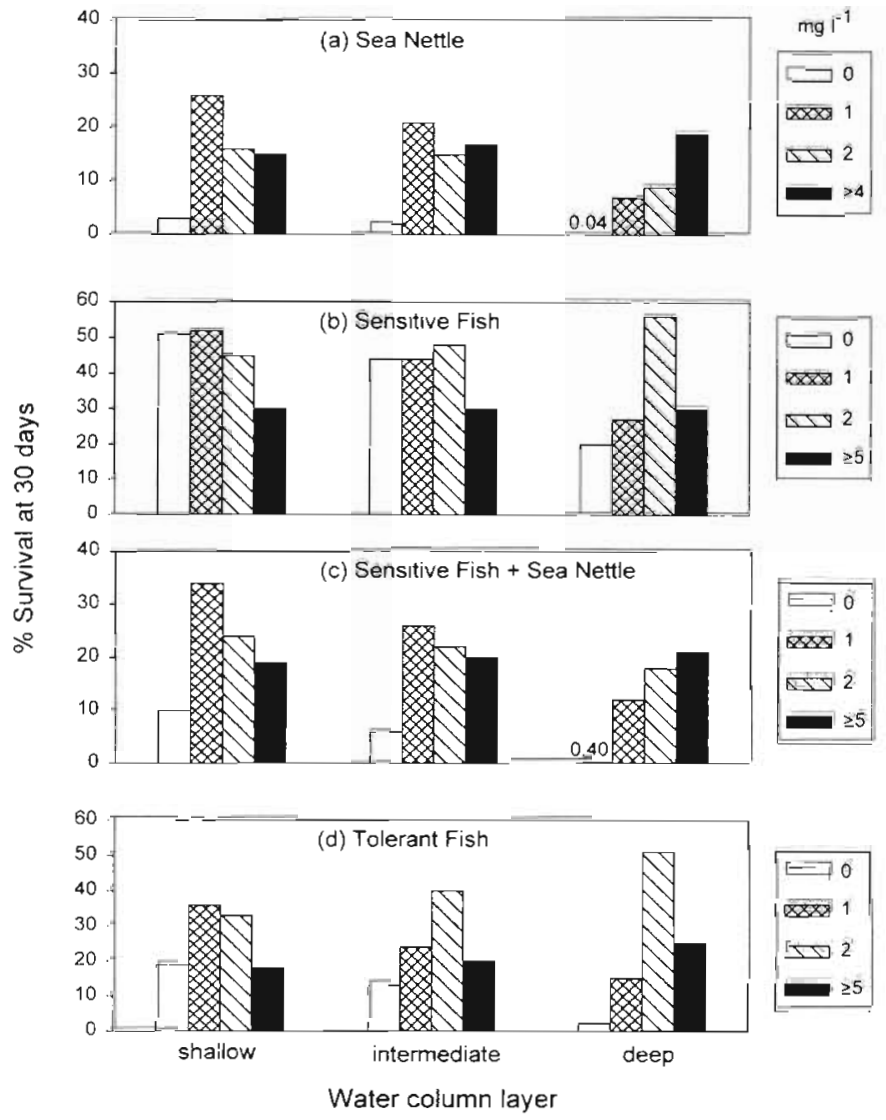

Fig. 3. Simulated larval survival (\%) to $30 \mathrm{~d}$ for 4 bottom dissolved oxygen concentrations in deep, intermediate, and shallow water columns. Survival is total survival throughout the water column. The only source of larval mortality considered in these simulations is predation. Predators simulated are (a) sea nettles, (b) sensitive fish, (c) tolerant fish, and (d) both sea nettles and sensitive fish

important (e.g. the effects of bottom dissolved oxygen varied with predator type), detailed descriptions of results for the 2 sets of simulations are provided below. However, several general patterns emerged. First, larval survival, averaged over all predator types and depths, was highest at intermediate bottom dissolved oxygen concentrations; percent survival at $30 \mathrm{~d}$ was $14 \%$ at $0 \mathrm{mg} \mathrm{l}^{-1}$ (i.e. 0.0 to $0.99 \mathrm{mg} \mathrm{l}^{-1}$ ), $27 \%$ at $1 \mathrm{mg} \mathrm{l}^{-1}$, $31 \%$ at $2 \mathrm{mg} \mathrm{l}^{-1}$ and $22 \%$ at 4 to $5 \mathrm{mg} \mathrm{l}^{-1}$ bottom dissolved oxygen. A bottom layer with high bottom dissolved oxygen rarely yielded the highest level of Iarval survival (Fig. 3). Second, bottom dissolved oxygen affected the relative predation potentials of the gelatinous and fish predators (Fig. 4). The importance of fish predation increased with increasing bottom dissolved oxygen. Third, predicted larval survival rates were more strongly affected by dissolved oxygen effects on vertical distribution and capture rates than by lowoxygen effects on larval growth rates (Table 2). Fourth, increasing water column depth consistently pushed 

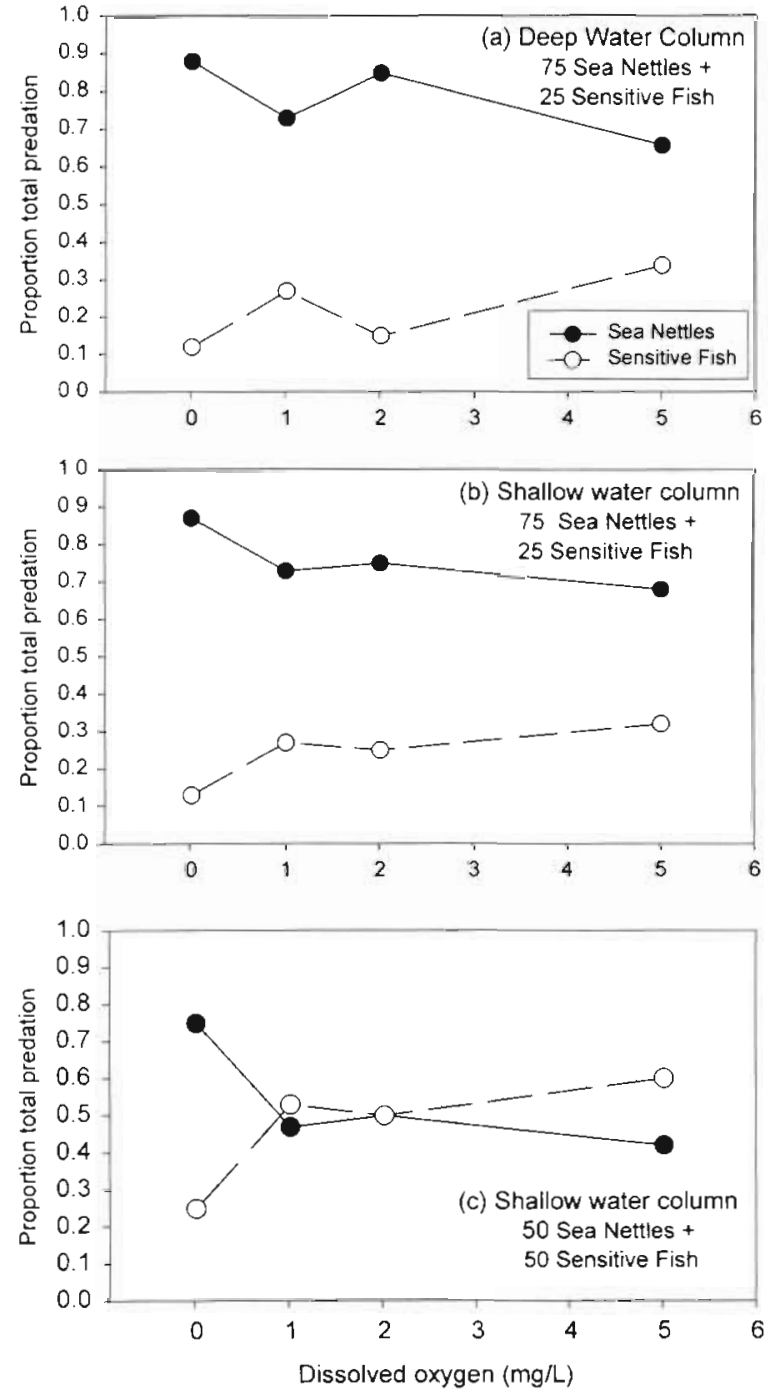

Fig. 4. Proportion of total simulated predation due to sea nettles versus the sensitive fish predator. Simulations include 0 , 1,2 and 5 (no-effect) $\mathrm{mg} \mathrm{l}^{-1}$ bottom dissolved oxygen concentrations in the (a) deep and (b) shallow water columns with 75 simulated sea nettles and 25 sensitive predatory fish (c) in the deep water column with 50 simulated sea nettles and 50 sensitive fish

maximum larval survival towards higher bottom dissolved oxygen concentrations (Fig. 3). Fifth, bottom dissolved oxygen strongly affected the location of trophic interactions within the water column (Fig. 5). Finally, predation rates were higher in sea nettle simulations than in simulations of fish predators (Fig. 3). However, because absolute predation rates in simulations (as opposed to effects of dissolved oxygen on predation rates) were strongly influenced by the densities of predators, which show high spatial and temporal variability in the field, and capture success, which varies among fish predators, differences between predators in absolute predation rates will not be considered further. Instead we focus on within-predatortype changes in predation rates, changes in the relative predation potential of different predators, and the location of predation events in response to dissolved oxygen concentration and water column depth.

\section{Effects of predator, dissolved oxygen, and water column depth}

\section{Sea nettle predation}

Lowest survival of fish larvae exposed to simulated sea nettles occurred at bottom dissolved oxygen concentrations of $0 \mathrm{mg} \mathrm{l}^{-1}$ in all 3 water column depths (Fig. 3a). Highest larval survival occurred at $1 \mathrm{mg} \mathrm{l}^{-1}$ in the shallow water column ( $25 \%$ of volume in bottom layer) and at $\geq 4 \mathrm{mg} \mathrm{l}^{-1}$ in the deep water column (70\% of the water volume in the bottom layer). All bottom oxygen concentrations $\geq 1 \mathrm{mg} \mathrm{l}^{-1}$ yielded similar larval survival in the intermediate depth water column $(40 \%$ of the volume in the bottom layer). Larval survival var-

Table 2. Ratios of larval survival when a single factor was not allowed to vary with dissolved oxygen to larval survival when all 3 factors were allowed to vary with dissolved oxygen. Ratio values $>1.0$ indicate that adjustment of the factor for dissolved oxygen effects caused a decrease in larval survival (i.e. adjusting the factor for dissolved oxygen effects increased predation mortality). Ratio values $<1.0$ indicate that the factor caused an increase in larval survival. Factors whose omission caused $\geq 50 \%$ change in larval survival (ratios $\leq 0.50$ or $\geq 1.50$ ) are indicated in bold

\begin{tabular}{|c|c|c|c|c|c|}
\hline Predator & $\begin{array}{l}\text { Bottom } \\
\text { dissolved } \\
\text { oxygen } \\
\left(\mathrm{mg} \mathrm{l}^{-1}\right)\end{array}$ & Factor & Shallow & $\begin{array}{c}\text { Inter- } \\
\text { mediate }\end{array}$ & Deep \\
\hline \multirow{6}{*}{$\begin{array}{l}\text { Sea } \\
\text { nettles }\end{array}$} & \multirow[t]{3}{*}{0} & Capture & 2.18 & 2.26 & 5.50 \\
\hline & & Distribution & 1.07 & 1.93 & 96.50 \\
\hline & & Growth & 1.60 & 1.69 & 2.25 \\
\hline & \multirow[t]{3}{*}{2} & Capture & 1.12 & 1.32 & 1.87 \\
\hline & & Distribution & 0.33 & 0.34 & 0.39 \\
\hline & & Growth & 1.26 & 1.24 & 1.40 \\
\hline \multirow{6}{*}{$\begin{array}{l}\text { Sensitive } \\
\text { fish }\end{array}$} & \multirow[t]{3}{*}{0} & Capture & 0.99 & 0.94 & 0.96 \\
\hline & & Distribution & 1.25 & 1.58 & 3.89 \\
\hline & & Growth & 0.96 & 0.96 & 0.96 \\
\hline & \multirow[t]{3}{*}{2} & Capture & 0.84 & 0.84 & 0.83 \\
\hline & & Distribution & 1.30 & 1.33 & 1.31 \\
\hline & & Growth & 0.98 & 0.95 & 0.90 \\
\hline \multirow{6}{*}{$\begin{array}{l}\text { Tolerant } \\
\text { fish }\end{array}$} & \multirow[t]{3}{*}{0} & Capture & 0.40 & 0.34 & 0.10 \\
\hline & & Distribution & 3.87 & 6.36 & 44.70 \\
\hline & & Growth & 0.89 & 0.86 & 0.77 \\
\hline & \multirow[t]{3}{*}{2} & Capture & 0.82 & 0.73 & 0.68 \\
\hline & & Distribution & 1.14 & 1.09 & 1.08 \\
\hline & & Growth & 1.02 & 0.88 & 0.88 \\
\hline
\end{tabular}



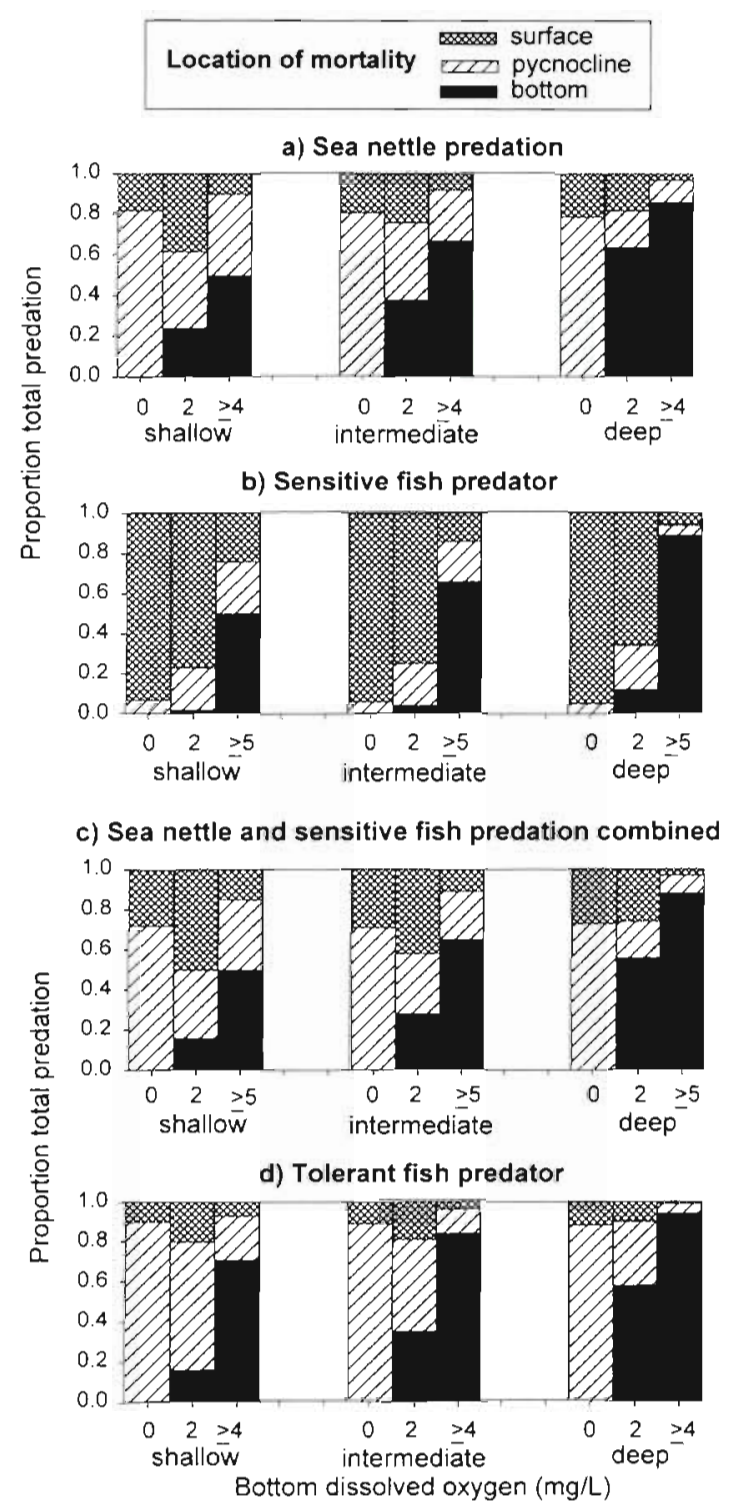

Fig. 5. Proportion of total simulated predation mortality that occurred in the surface, pycnocline, and bottom layers for 0,2 , and no-effects ( 4 or $5 \mathrm{mg} \mathrm{l}^{-1}$ ) bottom dissolved oxygen concentrations in the deep and shallow water columns. (a) Sea nettles, (b) sensitive fish, (c) sea nettle and sensitive fish combined simulations. and (d) tolerant fish

ied across bottom dissolved oxygen concentrations (maximum/minimum) from about 7 -fold in the shallow water column to more than an order of magnitude in the deep water column. Larval survival at all bottom dissolved oxygen concentrations $\leq 2 \mathrm{mg} \mathrm{l}^{-1}$ decreased with increasing water column depth.

When bottom dissolved oxygen concentrations were set to $0 \mathrm{mg} \mathrm{l}^{-1}$, the majority of sea nettle predation events $(\sim 80 \%)$ occurred in the pycnocline layer for all water column depths (Fig. 5a). Both larval prey and sea nettles shifted their vertical distributions into the pycn- ocline layer at low dissolved oxygen concentrations (Fig. 1a,b, based on Keister 1996) resulting in increased encounters.

At higher dissolved oxygen concentrations, the location of predation events varied with bottom dissolved oxygen concentration and water column depth (Fig. 5a). The majority of predation events occurred in the bottom layer at bottom dissolved oxygen concentrations of 2 and $4 \mathrm{mg} \mathrm{l}^{-1}$ in the deep water column, and at $\geq 4 \mathrm{mg} \mathrm{l}^{-1}$ in the intermediate and shallow water column depths. The proportion of predation events in the bottom layer increased with increasing bottom dissolved oxygen concentration and water column depth.

\section{Sensitive fish predator}

The effect of dissolved oxygen on larval survival differed between simulations of a predatory fish sensitive to low dissolved oxygen (Fig. 3b) and sea nettles (Fig. 3a) in 2 important ways: larval survival with sensitive fish predators was sometimes lowest with a welloxygenated bottom layer (rather than a $0 \mathrm{mg}^{-1}$ bottom layer), and survival was less variable among bottom oxygen simulations within any particular water column depth. Larval survival was lowest at $\geq 5 \mathrm{mg} \mathrm{l}^{-1}$ in the shallow and intermediate depth water columns, and at $0 \mathrm{mg} \mathrm{l}^{-1}$ in the deep water column. Highest larval survival occurred with a $1 \mathrm{mg} \mathrm{l}^{-1}$ dissolved oxygen bottom layer in the shallow water column, and with a $2 \mathrm{mg} \mathrm{l}^{-1}$ bottom layer in the intermediate depth and deep water columns. Survival with a $0 \mathrm{mg} \mathrm{l}^{-1}$ bottom layer was similar to that with a $1 \mathrm{mg} \mathrm{l}^{-1}$ bottom layer in all water columns, and decreased with increasing water column depth. The largest variation in larval survival occurred in the deep water column, where survival at $2 \mathrm{mg} \mathrm{l}^{-1}$ was $>2.5$ fold the survival at $0 \mathrm{mg} \mathrm{l}^{-1}$.

The majority of predation events occurred in the surface layer at bottom dissolved oxygen concentrations of 0 and $2 \mathrm{mg} \mathrm{l}^{-1}$ for all 3 water column depths (Fig. 5b). For bottom dissolved oxygen concentrations $\geq 5 \mathrm{mg} \mathrm{l}^{-1}$, the vertical distribution of predation events more closely resembled the relative proportions of the different layers in the 3 water column depths (i.e. predation in the bottom layer increased with water column depth). The proportion of predation events in the bottom layer increased, and in the pycnocline and surface layers decreased, with increasing water column depth.

\section{Sea nettle and sensitive fish predators combined}

Because of the densities of predators used in most simulations, predation was dominated by sea nettles in simulations where larvae were exposed to both sea 
nettles and the sensitive fish predator. Larval survival with both sea nettles and the sensitive predator (Fig. 3c) was similar in magnitude and exhibited the same pattern with bottom dissolved oxygen concentrations and water column depths as for sea nettles alone (Fig. 3a). Lowest survival occurred at $0 \mathrm{mg} \mathrm{l}^{-1}$ in all water column depths and highest larval survival occurred at $1 \mathrm{mg} \mathrm{l}^{-1}$ in shallow and intermediate water column depths and at $\geq 2 \mathrm{mg} \mathrm{l}^{-1}$ in the deep water column.

An important result of these combined simulations is the finding that the relative importance of predation by the 2 predators varied with bottom dissolved oxygen concentration (Fig. 4). In the deep water column, the proportion of total predation caused by sea nettles was 7 -fold higher than that caused by sensitive fish at $0 \mathrm{mg}$ $1^{-1}$, but $<2$-fold higher than that caused by sensitive fish at $5 \mathrm{mg} \mathrm{l}^{-1}$ bottom dissolved oxygen. Similarly, the relative importance of sea nettles and sensitive fish in the shallow water column simulations differed most at a bottom oxygen concentration of $0 \mathrm{mg} \mathrm{l}^{-1}$ (more than 7 -fold) and least at $5 \mathrm{mg} \mathrm{l}^{-1}$ (approximately 2-fold). In simulations with higher densities of fish predators or lower densities of sea nettles the dominant predator could vary with bottom dissolved oxygen. For example, in simulations with 50 sea nettles and 50 sensitive fish predators, the majority of larval predation mortality was due to sea nettles at $0 \mathrm{mg} \mathrm{i}^{-1}$ dissolved oxygen, but the majority of predation was due to fish at higher oxygen concentrations (Fig. 4c).

Predation was heavily concentrated in the pycnocline layer of the water column when bottom dissolved oxygen was $0 \mathrm{mg} \mathrm{l}^{-1}$ in the standard simulations with 75 sea nettles and 25 sensitive fish predators (Fig. $5 \mathrm{c}$ ). At other dissolved oxygen concentrations, the proportion of predation events in the bottom layer increased. Larvae that moved into the surface layer suffered similar levels of predation by sea nettles and by fish, while larvae in the pycnocline were preyed upon primarily by sea nettles. The spatial pattern of each predatortype's predation was similar in combined simulations to that found when the predators were simulated separately (Fig. 5a,b).

\section{Tolerant fish predator}

Larval survival differed between the tolerant and sensitive fish predators in several ways. Larval survival was consistently lower at a given dissolved oxygen concentration for the tolerant fish predator (Fig. 3d) compared to the sensitive fish predator (Fig. 3b). Also, the lowest survival generally occurred at $0 \mathrm{mg} \mathrm{l}^{-1}$ bottom dissolved oxygen for the tolerant fish predator but not for the sensitive fish predator. With increasing water column depth, larval survival in the $0 \mathrm{mg} \mathrm{l}^{-1}$ and no-effect ( $\geq 4$ or $5 \mathrm{mg} \mathrm{l}^{-1}$ ) simulations became more dissimilar for the tolerant fish predator but more similar for the sensitive fish predator. While the highest larval survival occurred at 1 or $2 \mathrm{mg} \mathrm{l}^{-1}$ bottom dissolved oxygen for both predators, the difference in survival between the 1 to $2 \mathrm{mg} \mathrm{l}^{-1}$ and $0 \mathrm{mg} \mathrm{l}^{-1}$ simulations was greater for the tolerant fish predator than for the sensitive fish predator.

The spatial pattern of predation with the tolerant fish predator (Fig. 5d) was more similar to that generated by the sea nettle (Fig. 5a) than that by the sensitive fish predator (Fig, 5b). As with the sea nettle predator, most predation events for the tolerant fish predator occurred in the pycnocline layer when bottom oxygen concentrations were $0 \mathrm{mg} \mathrm{l}^{-1}$, and in the bottom and pycnocline layers with bottom oxygen concentrations $\geq 2 \mathrm{mg}$ $\mathrm{l}^{-1}$. Less predation occurred in the surface layer in simulations with the tolerant fish predator than in those with a sensitive fish predator at 0 and $2 \mathrm{mg} \mathrm{l}^{-1}$ bottom dissolved oxygen.

\section{Prey depletion}

The description and analyses of model results above relies on the number of larvae surviving at the end of the $30 \mathrm{~d}$ simulation to compare effects of bottom dissolved oxygen under a variety of scenarios. However, in a number of cases the potential magnitude of predation mortality, and the magnitude of the differences in predation mortality among bottom dissolved oxygen concentrations, was reduced because of prey depletion at the bottom dissolved oxygen yielding the greatest predation. This effect was most pronounced in the deep water column with predation by sea nettles, sea nettles and sensitive fish together, and tolerant fish (Fig. 6). In each of these cases the difference in the number of surviving larvae in the $0 \mathrm{mg} \mathrm{l}^{-1}$ bottom dissolved oxygen and the higher dissolved oxygen simulations is much greater early in the simulation than on Day 30. Although prey depletion reduced the apparent magnitude of dissolved oxygen effects in several simulations, it did not affect the rank order of survival in the various oxygen concentrations simulated. Predicted patterns of larval survival are therefore robust with respect to the duration of simulations used to compute survival rates.

\section{Contribution of capture, distributional, and growth effects}

Capture success and distributional effects of bottom layer oxygen depletion had greater influence on pre- 

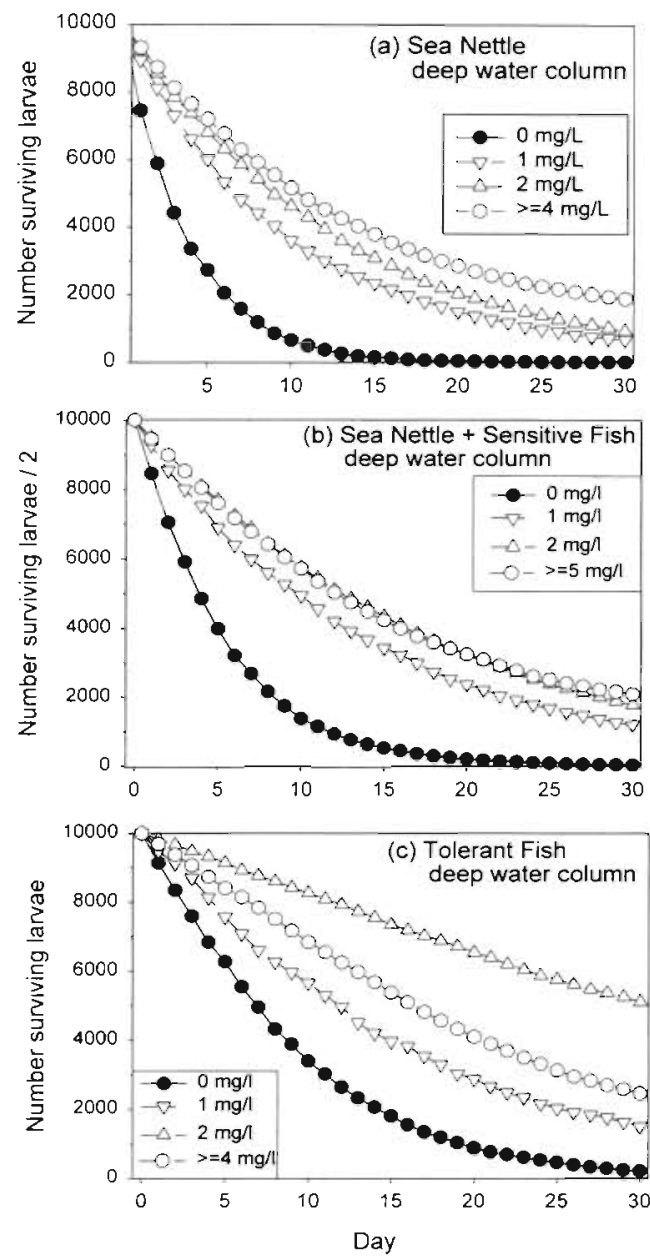

Fig. 6. Daily numbers of surviving larvae in simulations of a deep water column for $0,1,2$, and no-effect $\left(4\right.$ or $\left.5 \mathrm{mg} \mathrm{l}^{-1}\right)$ dissolved oxygen concentrations. Time series are presented for simulations in which the effect of dissolved oxygen on larval survival was substantially greater early in the simulation than on Day 30. (a) Sea nettles, (b) sea nettle and sensitive fish combined simulations, and (c) tolerant fish

dation mortality than did growth effects (Table 2). In general, the magnitude of capture and distributional effects increased with water column depth (i.e. with the percentage of the water column in the bottom layer), and were greater at $0 \mathrm{mg} \mathrm{l}^{-1}$ bottom dissolved oxygen than at $2 \mathrm{mg} \mathrm{l}^{-1}$.

The direction of capture and distributional effects depended on the predator type and dissolved oxygen concentration (Table 2). The effects of dissolved oxygen on capture success increased predation mortality (ratios $>1.0$ ) of fish larvae exposed to sea nettles, decreased predation mortality (ratios $<1.0$ ) of fish larvae exposed to tolerant fish predators, and had little effect on predation mortality caused by sensitive fish. Avoidance of a $0 \mathrm{mg} \mathrm{l}^{-1}$ bottom layer by both predators and larval prey concentrated organisms in the remain- ing water layers and increased predation mortality of larvae exposed to all predators. In the deep water column, these distributional effects resulted in 4 -fold (sensitive fish predators) to approximately 1.5 to 2 orders of magnitude (sea nettles and tolerant fish predators) increases in predation mortality. In contrast, differences between the distributional responses of sea nettles and fish larvae in a water column with a $2 \mathrm{mg}$ $1^{-1}$ bottom layer reduced predation mortality by about 60 to $70 \%$.

Larval growth effects were relatively small compared to capture success and distributional effects, but were not inconsequential. At bottom dissolved oxygen concentrations of $0 \mathrm{mg} \mathrm{l^{-1 }}$, larval growth effects caused about a 60 to $125 \%$ reduction in survival of larvae preyed upon by sea nettles, and a $23 \%$ increase in larval survival for the tolerant fish predator in the deep water column. In general, growth effects caused reduced larval survival with sea nettle predation, but had little effect or increased larval survival with fish predation

\section{DISCUSSION}

Our analysis indicates that bottom dissolved oxygen can strongly affect predation mortality of fish larvae throughout the water column because of its effect on the vertical distributions of larvae and their predators, the ability of predators to capture larvae, and the growth rate of larvae. Thus, there is the potential for eutrophication to strongly affect larval survival, and possibly fish recruitment, even in the absence of direct effects of low oxygen on mortality of larvae, or effects of nutrient enrichment on the abundance of larval prey or predators. For any particular water column depth and predator combination, variation in bottom dissolved oxygen during a $30 \mathrm{~d}$ simulated larval duration led to variation in larval survival ranging from between $60 \%$ to more than an order of magnitude. Not surprisingly, the importance of the dissolved oxygen effect increased with increasing water column depth as larger proportions of the water column became subject to oxygen depletion.

While predicted larval survival depended on the particular combinations of predator type, bottom dissolved oxygen concentration, and water column depth, several general patterns emerged. First, larval survival was generally highest in a water column with a hypoxic (1 to $2 \mathrm{mg} \mathrm{l}^{-1}$ dissolved oxygen) bottom layer. A water column with all water layers at or above dissolved oxygen concentrations that had no effect on larval growth or the distribution of capture rates of predators (the pristine condition in many systems) rarely yielded the highest larval survival. Only in the deep 
water column with sea nettles as the sole predator, or sea nettles and sensitive fish in a 3:1 ratio ( 75 and 25 individuals of each), was larval survival highest at the highest bottom dissolved oxygen concentration simulated.

Second, lowest larval survival always occurred with either a very low (dissolved oxygen concentrations of 0.00 to $0.99 \mathrm{mg} \mathrm{l}^{-1}$ ) or very high dissolved oxygen bottom layer. An anoxic or severely hypoxic bottom layer often led to extremely low larval survival even in the absence of any direct mortality caused by exposure to low oxygen concentrations. Instead, high predation mortality resulted primarily from larvae and their predators crowding into the surface and pycnocline layers, greatly increasing their encounter rates. For sea nettle predators, the increase in encounter rates in pycnocline and surface layers counteracted the decrease in capture success of larvae by sea nettles at high dissolved oxygen concentrations. Both larvae and sea nettles preferentially utilize the relatively thin pycnocline layer when bottom waters are anoxic. In contrast to sea nettles, the sensitive fish predator we simulated preferred surface waters when the bottom layer oxygen concentration was extremely low, resulting in a mismatch between larval prey and predatory fish distributions. Nevertheless, highest predation mortality by sensitive fish in the deep water column occurred when bottom waters were $0 \mathrm{mg} \mathrm{l}^{-1}$. In this case, such a large portion of the water column was avoided that the effect of crowding in the remaining water column was sufficiently strong to overcome the differences in vertical distributions of larvae and their predators. In shallower water columns, highest predation mortality from sensitive fish occurred when oxygen concentrations were high in the bottom layer, allowing access to the entire water column and maximum capture rates when larvae were encountered. The same predator-specific characteristics appeared to be responsible for the patterns of predation whether the predators were tested singly or in combination.

Third, the physiological (e.g. larval growth) and behavioral responses to dissolved oxygen of each individual species involved in the predator-prey interaction were important. Effects of dissolved oxygen on growth, distribution and prey capture rates all contributed to the overall effects of dissolved oxygen on predation mortality seen in these simulations. However, the relative importance of each of those factors, as well as the magnitude and direction of their effects varied among predators and with the oxygen structure of the water column.

Fourth, the oxygen structure of the water column, and the response of predators and prey to that oxygen structure, strongly influenced the spatial focus of trophic interactions. The distributional responses to bottom oxygen concentration are overlain on other behaviors such as migrations, predator avoidance and prey tracking, as well as on the effect of oxygen on predation behaviors and prey escape. As a result, the oxygen structure of the water column can exert a strong effect on spatial patterns of secondary production even in the absence of direct effects of low oxygen on mortality.

Finally, distributional and capture success responses to low dissolved oxygen concentrations were more important than larval growth rate responses. The examination of the relative importance of distribution, capture success and growth responses to low oxygen illustrates the complexity of the relationship among responses to low oxygen and predation mortality of larvae both in the simulations and in nature. Both laboratory and field data suggest that larval and juvenile fishes avoid the bottom layer of the water column (i.e. respond to low oxygen by changing their vertical distribution) when bottom oxygen concentrations are lethal or low enough to strongly reduce growth. Growth effects in the simulations were likely less important than distribution and capture success effects in simulations because larvae tended to avoid dissolved oxygen concentrations with the greatest growth penalties, because of the relationships between prey size and predator capture success used in simulations, and because larvae were redistributed throughout the water column each day. This last feature of the model follows from the reasonable assumption that larvae capable of avoiding low oxygen will probably not remain in conditions that lead to mortality or severely reduced growth even if they spend some fraction of their time in such a suboptimal habitat. The daily redistribution of larvae results in $30 \mathrm{~d}$ growth of individuals averaging reduced growth experienced during days spent in the bottom layer (when bottom dissolved oxygen is $<4 \mathrm{mg} \mathrm{l}^{-1}$ ) and higher growth during days spent in the pycnocline or surface layer. In addition. the effects of growth may have been stronger if simulations were run until each larva attained a fixed size rather than a fixed age. The effect of slow growth can be a prolonged period of vulnerability to predators whose capture rates decrease with increasing prey size. Running the model for a fixed $30 \mathrm{~d}$ time period precluded testing for this effect.

Distributional shifts in response to other species in the environment, such as alternative prey, can also influence the relative direction and magnitude of the effect on predation mortality of oxygen-related distributional responses. For example, in our simulations avoidance by both sea nettles and fish larvae of a bottom layer with dissolved oxygen concentrations $<1 \mathrm{mg}$ $\mathrm{I}^{-1}$ increased encounter rates and greatly increased predation mortality of the larvae. However, when bot- 
tom oxygen concentrations are $2 \mathrm{mg} \mathrm{l}^{-1}$ (i.e. 2.0 to $2.9 \mathrm{mg} \mathrm{I}^{-1}$ ) sea nettles avoid the bottom layer more strongly than do fish larvae (Keister 1996), and distributional responses at $2 \mathrm{mg} \mathrm{l}^{-1}$ bottom dissolved oxygen reduced predation mortality caused by sea nettles feeding on larvae. This avoidance of a moderately hypoxic bottom layer by sea nettles is unlikely to be a direct response to low oxygen since $96 \mathrm{~h}$ survival of sea nettles held at $1 . \mathrm{mg} \mathrm{J}^{-1}$ dissolved oxygen is $100 \%$ (E Houde unpubl. data). Instead, sea nettles may track the vertical distribution of their more sensitive copepod prey (Keister 1996). The relative importance and direction of effects of capture success, distributional changes, and growth rates will also likely vary for other predator types and prey species.

Overall, our model analyses indicate that dissolved oxygen imparts a substantial degree of spatial structure to the water column that can alter the qualitative as well as quantitative results of predator-prey interactions. In systems where the predation potential of medusae and dissolved-oxygen-sensitive predatory fish are similar, the predator responsible for the majority of predation events (and therefore transfer of carbon from larvae to predators) will vary with bottom dissolved oxygen and water column depth. Simulations with additional prey taxa (such as crustacean zooplankton) could provide a basis for predicting how the oxygen structure of the water column further affects larval fish, predatory fish and sea nettle abundances and carbon flow through plankton in the Chesapeake Bay. The approach presented here should be applicable to a wide range of aquatic systems where density stratification and excess nutrient loading from anthropogenic sources leads to bottom-layer oxygen depletion.

\section{Limitations of model}

Several limitations of the predation model presented are important to note. The first is the need for better data on the effect of bottom dissolved oxygen on the vertical distribution of fish predators of larvae. Results of this model clearly indicate that more detailed information is needed not only on avoidance of oxygendepleted bottom waters, which is available for a number of fish species (e.g. Howell \& Simpson 1994), but also on the preferred position within the water column for individuals that are avoiding the bottom water layer. Second, the current predation model simulates a single cohort for $30 \mathrm{~d}$. Relating model predictions to year class success requires the simulation of multiple cohorts exposed to a mix of predators for the portion of their early life history through the stage at which recruitment is set, as well as inclusion of other potential sources of egg and larval mortality. Third, eutroph- ication effects other than oxygen depletion will be important to consider in more elaborate models designed to evaluate the effects of nutrient levels on fish recruitment. Nutrient effects on the abundance of prey of larval fishes may have an important effect on larval growth rates, and therefore their age-specific vulnerability to predation. Finally, a better understanding of how low oxygen affects the various components of predator-prey interactions (attack rates, escape success, etc.) would provide a better understanding of the mechanisms by which low dissolved oxygen affects trophic interactions in general, and enhance our ability to make predictions about species that have not been specifically tested. Despite these limitations, the models described here provide important information on how eutrophication can affect survival of larvae of summer-breeding estuarine fishes.

\section{Management implications}

The low survival of fish larvae in some simulations of high bottom dissolved oxygen indicates that caution is required in assuming that improving water quality will automatically increase larval survival. The potential for decreased nutrients to result in decreased biomass of fishes is implicit in broad geographic comparisons of nutrient loading and fisheries yields (Nixon 1986. Caddy 1993). The presumed mechanism causing this relationship is the effect of nutrients on prey abundance, and therefore on the growth, survival and fecundity of fishes. Hypotheses for high nutrient loadings reducing fish populations because of an effect on bottom-layer oxygen concentrations have generally invoked avoidance behavior (Howell \& Simpson 1994), a combination of avoidance and physiological stress for species sensitive to both high surface layer temperatures and low dissolved oxygen (e.g. the 'temperatureoxygen squeeze' hypothesis: Coutant 1985) and direct mortality (Breitburg 1992). Our model suggests another important pathway-altered predation mortality-by which changes in nutrient loads could either increase or decrease larval fish survival depending on the behaviors and tolerances of important predators in a vertically stratified system. In many of our simulations, increasing bottom dissolved oxygen concentrations from $<1 \mathrm{mg} \mathrm{l}^{-1}$ to bottom concentrations of 1 to $2 \mathrm{mg} \mathrm{l}^{-1}$ resulted in substantial increases in larval survival. However, further increases in bottom dissolved oxygen sometimes decreased larval survival as predators gained access to the entire water column at oxygen concentrations that resulted in maximum capture rates.

In the Chesapeake system, reduced nutrient loadings and consequent improvement in bottom dissolved 
oxygen concentrations could have a range of effects on predation mortality of fish larvae because spatial variation in bottom dissolved oxygen may remain high and hypoxia will not be eliminated in much of the system (United States Environmental Protection Agency Chesapeake Bay Program unpubl. data). Subpycnocline waters in parts of the mainstem Bay and many of the tributaries are predicted to experience hypoxia even with nutrients reduced to the limits of technology because of strong density stratification and low summer flushing rates. Spatial variation in depth among areas experiencing hypoxia should also lead to spatial variation in the effect of dissolved oxygen on predation mortality of larval fishes. In general, as the percentage of the water column that was susceptible to low oxygen increased in simulations, the magnitude of the effect of bottom oxygen concentration on larval survival and the dissolved oxygen concentration yielding highest larval survival both increased.

In addition to variation in responses of different physical systems, variation in responses of different trophic categories is important. Specifically, the target of management concerns will need to be considered. For example, if maximizing the feeding ability of juvenile striped bass is a primary management focus, dissolved oxygen concentrations that yield the highest opportunity for predator and prey encounters and high capture success rates may be considered to be beneficial rather than harmful, even though these conditions may yield the lowest survival of larvae of summerbreeding fishes exposed to fish predation.

Acknowledgements. We thank E. Houde and J. Keister for comments on a previous draft of the manuscript and for collaboration in the field and experimental work that generated data used in these models. Comments by J. Rice and 3 anonymous reviewers were also helpful in improving the manuscript. Funding for this project was provided by the University of Maryland Sea Grant Program (Grant R/F-79 to S. Brandt and D.L.B.), NOAA Coastal Ocean Program to the COASTES program, and by the Electric Power Research Institute under contract RP2932 (DOE number ERD-87-672) with the United States Department of Energy, under contract DE-AC05960R22464 with Lockheed Martin Energy Research Corporation. This is publication 4867 of the Environmental Sciences Division, ORNL.

\section{LITERATURE CITED}

Bailey KM, Batty RS (1983) A laboratory study of predation by Aurelia aurita on larval herring (Clupea harengus): experimental observations compared with model predictions. Mar Biol 72:295-301

Bejda AJ, Studholme AL, Olla BL (1987) Behavioral responses of red hake, Urophycis chuss, to decreasing concentrations of dissolved oxygen. Environ Biol Fish 19:261-268

Blaxter JHS (1986) Development of sense organs and behav- ior of teleost larvae with special reference to feeding and predator avoidance. Trans Am Fish Soc 115:98-114

Breitburg DL (1989) Demersal schooling by settlement-stage naked goby larvae. Environ Biol Fish 26:97-103

Breitburg DL (1992) Episodic bypoxia in the Chesapeake Bay: interacting effects of recruitment, behavior and physical disturbance. Ecol Monogr 62:525-546

Breitburg DL (1994) Behavioral response of fish larvae to low dissolved oxygen concentrations in a stratified water column. Mar Biol 120:615-625

Breitburg DL, Steinberg N, DuBeau S, Cooksey C, Houde ED (1994) Effects of low dissolved oxygen on predation on estuarine fish larvae. Mar Ecol Prog Ser 104:235-246

Breitburg DL, Loher T, Pacey CA, Gerstein A (1997) Varying effects of low dissolved oxygen on trophic interactions in an estuarine food web. Ecol Monogr 67:489-507

Brownlee DC, Jacobs F (1987) Contaminant problems and management of living Chesapeake Bay resources. In: Majumdar SK, Hall LW Jr, Austin HM (eds) Mesozooplankton and microzooplankton in the Chesapeake Bay. Pa Acad Sci Publ, Philadelphia, p 217-269

Boynton WR, Polgar TT, Zion HH (1981) Importance of juvenile striped bass food habits in the Potomac Estuary. Trans Am Fish Soc 110:56-63

Caddy JF (1993) Toward a comparative evaluation of human impacts on fishery ecosystems of enclosed and semienclosed seas. Rev Fish Sci 1:57-95

Coutant CC (1985) Striped bass, temperature, and dissolved oxygen: a speculative hypothesis for environmental risk. Trans Am Fish Soc 114:31-61

Cowan JH Jr, Houde ED (1990) Growth and survival of bay anchovy Anchoa mitchilli larvae in mesocosm enclosures. Mar Ecol Prog Ser 68:47-57

Cowan JH Jr, Houde ED (1992) Size-dependent predation on marine fish larvae by ctenophores, scyphomedusae and planktivorous fish. Fish Oceanogr 1:113-126

Cowan JH Jr, Houde ED (1993) Relative predation potentials of scyphomedusae, ctenophores and planktivorous fish on ichthyoplankton in Chesapeake Bay. Mar Ecol Prog Ser 95:55-65

Cowan JH Jr, Birdsong RS, Houde ED. Priest JS, Sharp WC, Mateja GB (1992) Enclosure experiments on survival and growth of black drum eggs and larvae in lower Chesapeake Bay. Estuaries 15:492-502

Cowan JH Jr, Houde ED, Rose KA (1996) Size-dependent vulnerability of marine fish larvae to predation: an individualbased numerical experiment. ICES J Mar Sci 53:23-37

Cowan JH Jr, Rose KA, Houde ED (1997) Size-based foraging success and vulnerability of predation: selection of survivors in individual-based models of larval fish populations. In: Chambers RC, Trippel EA (eds) Early life history and recruitment in fish populations. Chapman and Hall, London, p 357-386

Dalton P (1987) Ecology of Anchoa mitchilli eggs and larvae in the mid-Chesapeake Bay. MSc thesis, University of Maryland, Solomons

Dovel WL (1971) Fish eggs and larvae of the Upper Chesapeake Bay. Special Rep 4, University of Maryland Natural Resources Institute, Solomons

Fuiman LA, Gamble JC (1989) Influence of experimental manipulations on predation of herring larvae by juvenile herring in large enclosures. Rapp PV Reun Cons Int Explor Mer 191:359-365

Gerritsen J, Strickler JR (1977) Encounter probabilities and community structure in zooplankton: a mathematical model. J Fish Res Bd Can 34:77-82

Horwitz RJ (1987) Fish. In: Heck KL Jr (ed) Lecture notes 
on coastal and estuarine studies. Springer-Verlag, Berlin, p $167-224$

Howell P, Simpson D (1994) Abundance of marine resources in relation to dissolved oxygen in Long Island Sound. Estuaries 17:394-402

Huffaker CB (1958) Experimental studies on predation: dispersion factors and predator-prey oscillations. Hilgardia $27: 343-383$

Keister JE (1996) Habitat selection and predation risk: effects of hypoxia on zooplankton and fish larvae in Chesapeake Bay. MSc Thesis, University of Maryland, College Park

Kemp WM, Boynton WR (1992) Benthic-pelagic interactions: nutrient and oxygen dynamics. In: Smith $D E$, Leffler $M$, Mackiernan G (eds) Oxygen dynamics in the Chesapeake Bay: a synthesis of recent research. Maryland Sea Grant College, University of Maryland, College Park, p 149-221

Kolar CS, Rahel FJ (1993) Interaction of a biotic factor (predator presence) and an abiotic factor (low oxygen) as an influence on benthic invertebrate communities. Oecologia 95:210-219

Luecke C, O'Brien WJ (1981) Prey location volume of a planktivorus fish: a new measure of prey vulnerability. Can $J$ Fish Aquat Sci 38:1264-1270

Magnuson JJ, Beckel AL, Mills K, Brandt SB (1985) Surviving winter hypoxia: behavioral adaptations of fishes in a northern Wisconsin winterkill lake. Environ Biol Fish 14: 241-250

Markle DF, Grant GC (1970) The summer food habits of young-of-year striped bass in three Virginia rivers. Chesapeake Sci 11:50-54

May EB (1973) Extensive oxygen depletion in Mobile Bay, Alabama. Limnol Oceanogr 18:353-366

Molofsky J (1994) Population dynamics and pattern formation in theoretical populations. Ecology $75(1): 30-39$

Nixon SW (1986) Nutrient dynamics and the productivity of marine coastal waters. In; Halwagy $R$, Clayton D, Behbehani $M$ (eds) Marine environment and pollution. The Alden Press, Oxford, p 97-115

Nixon SW (1992) Quantifying the relationship between nitrogen input and the productivity of marine ecosystems. Pro Adv Mar Tech Conf 5:57-83

Nixon SW (1995) Coastal marine eutrophication: a definition, social causes, and future concerns. Ophelia 41:199-219

Olson MM (1987) Zooplankton. In: Heck KL Jr (ed) Lecture notes on coastal and estuarine studies. Springer-Verlag, Berlin, p 38-81

Petersen JK, Pihl L (1995) Responses to hypoxia of plaice, Pleuronectes platessa, and dab, Limanda limanda, in the south-east Kattegat: distribution and growth. Environ Biol Fish $43: 311-321$

Editorial responsibility: Jennifer Purcell (Contributing Editor), Cambridge, Maryland, USA.
Pihl L, Baden SP, Diaz RJ, Schaffner LC (1992) Hypoxiainduced structural changes in the diet of bottom-feeding fish and crustacea. Mar Biol 112:349-361

Poulin R, Wolf NG, Kramer DL (1987) The effect of hypoxia on the vulnerability of guppies (Poecilia reticulata, Poeciliidae) to an aquatic predator (Astronotus ocellatus, cichlidae). Environ Biol Fish 20:285-292

Purcell JE, Nemazie DA, Dorsey SE, Houde ED, Gamble JC (1994) Predation mortality of bay anchovy Anchoa mitchilli eggs and larvae due to scyphomedusae and ctenophores in Chesapeake Bay. Mar Ecol Prog Ser 114 $47-58$

Rabalais NN, Turner RE, Wiseman WJ Jr, Boesch DF (1991) A brief summary of hypoxia on the northern Gulf of Mexico continental shelf: 1985-1988. In: Tyson RV, Pearson TH (eds) Modern and ancient continental shelf anoxia. Geological Society Special Publication No. 58, The Geological Society, London, p 35-47

Rahel FJ, Kolar CS (1990) Trade-offs in the response of mayflies to low oxygen and fish predation. Oecologia 84 : $39-44$

Rahel FJ, Nutzman JW (1994) Foraging in a lethal environment: fish predation in toxic waters of a stratified lake. Ecology 75:1246-1253

Roman MR, Gauzens AL, Rhinehart WK, White JR (1993) Effects of low oxygen waters on Chesapeake Bay zooplankton. Limnol Oceanogr 38:1603-1614

Rosenberg R (1990) Negative oxygen trends in Swedish coastal bottom waters. Mar Pollut Bull 21:335-339

Rosenthal H, Hempel G (1970) Experimental studies in feeding and food requirements of herring larvae (Clupea harengus L.). In: Steele JH (ed) Marine food chains. University of California Press, Berkeley, p 344-364

Rudstam LG, Magnuson JJ (1985) Predicting the vertical distribution of fish populations: analysis of cisco. Coregonus artedii, and yellow perch Perca flavescens. Can J Fish Aquat Sci 42:1178-1188

Sewell RBS, Fage L (1948) Minimum oxygen layer in the ocean. Nature 163:949-951

Taft JL, Taylor WR, Hartwig EO, Loftus R (1980) Seasonal oxygen depletion in Chesapeake Bay. Estuaries 4:242-247

Tilman D (1994) Competition and biodiversity in spatially structured habitats. Ecology 75:2-16

Walton WE, Easter SS Jr, Malinoski C, Hairston NG Jr (1994) Size-related change in the visual resolution of sunfish (Lepomis spp.). Can J Fish Aquat Sci 51:2017-2026

Ware DM (1978) Bioenergetics of pelagic fish: theoretical change in swimming speed and ration with body size. J Fish Res Bd Can 35:220-228

Wetzel RG (1983) Limnology. Saunders, Philadelphia

Submutted: November 25, 1997; Accepted: Novernber 3, 1998 Proofs received from author(s): March 2, 1999 